\title{
Larval \\ Transport and Dispersal \\ in the Coastal Ocean and \\ Consequences for \\ Population Connectivity
}

BY JESÚS PINEDA, JONATHAN A. HARE, AND SU SPONAUGLE

MANY MARINE SPECIES have small, pelagic early life stages. For those species, knowledge of population connectivity requires understanding the origin and trajectories of dispersing eggs and larvae among subpopulations. Researchers have used various terms to describe the movement of eggs and larvae in the marine environment, including larval dispersal, dispersion, drift, export, retention, and larval transport. Though these terms are intuitive and relevant for understanding the spatial dynamics of populations, some may be nonoperational (i.e., not measurable), and the variety of descriptors and approaches used makes studies difficult to compare. Furthermore, the assumptions that underlie some of these concepts are rarely identified and tested. Here, we describe two phenomenologi-

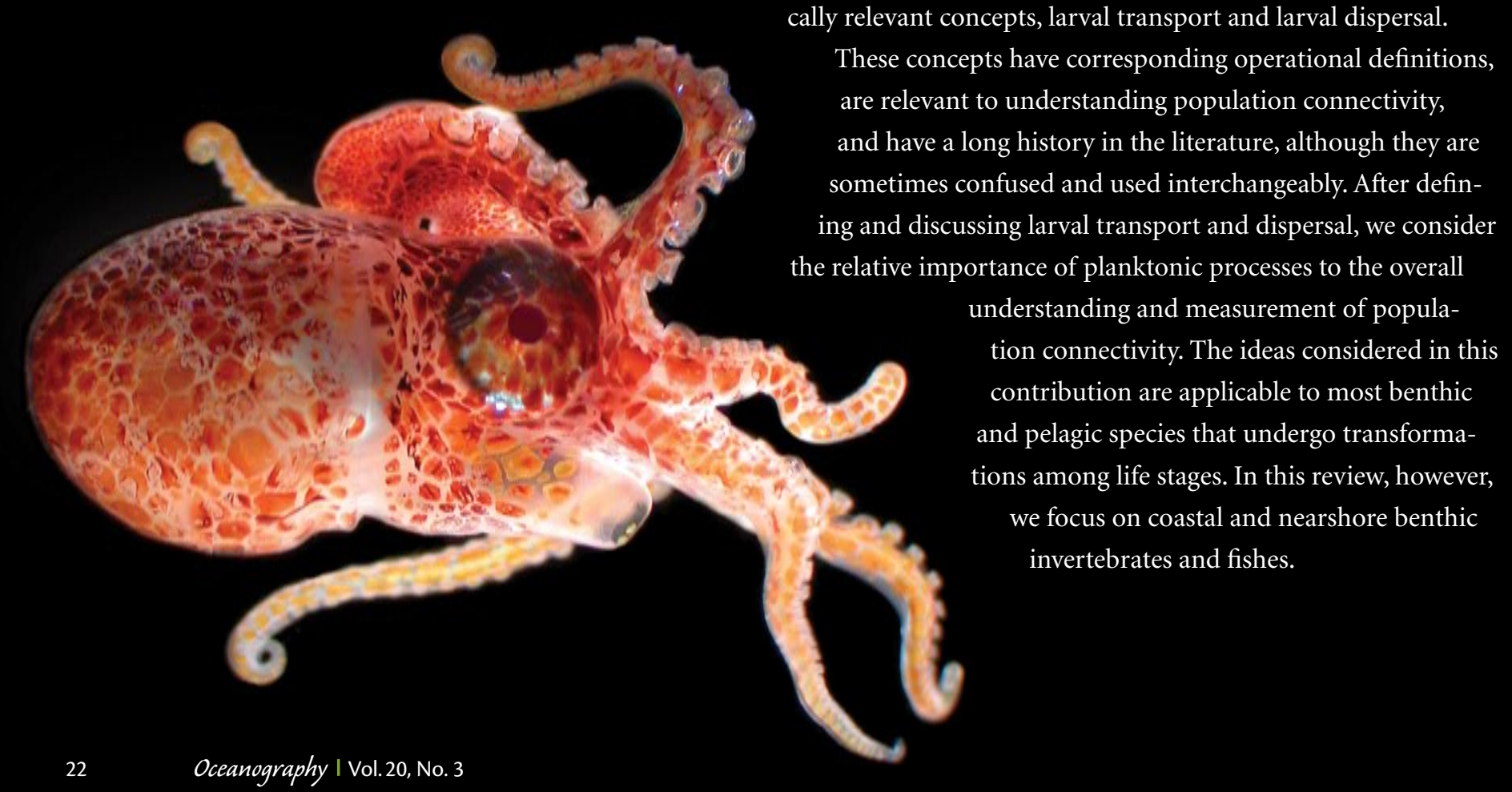


Larval transport is defined as the horizontal translocation of a larva between points $\mathrm{x}_{1}, \mathrm{y}_{1}$ and $\mathrm{x}_{2}, \mathrm{y}_{2}$, where $\mathrm{x}$ and $\mathrm{y}$ are horizontal axes, say, perpendicular and parallel to the coastline. In larval transport, only the spatial dimensions matter. Although this definition ignores the vertical axis $(\mathrm{z})$ for simplicity, this dimension is critical for larval transport because larvae can modify their horizontal distribution by swimming vertically, thereby encountering different currents (Nelson, 1912; Crisp, 1976). To transfer from point $\mathrm{x}_{1}, \mathrm{y}_{1}$ to point $\mathrm{x}_{2}, \mathrm{y}_{2}, \mathrm{a}$ larva can swim horizontally and may be transported by diffusive and advective processes (Scheltema, 1986). Defined as the translocation of a larva between two points, larval transport appears deceptively simple. However, the wide range of larval behaviors and physical mechanisms, together with their variability at multiple scales, makes larval transport exceedingly difficult to measure. The temporal and spatial scales of variability are enormous (Scheltema, 1986), even when considering a single physical transport mechanism (see Box 1).

In contrast, larval dispersal refers to the spread of larvae from a spawning source to a settlement site. This definition is consistent with the terrestrial literature (natal dispersal in Clobert et al., 2001; Begon et al., 2006) that describes seed dispersal as the probability density function of the number of seeds versus distance from the adult source (i.e., the dispersal kernel) (Nathan and Muller-Landau, 2000; see Gerrodette, 1981, for a rare marine example). Using the dispersal kernel, dispersal can be viewed as a probability that a released zygote will make it to settlement over a certain distance, herein referred to as dispersal distance. Larval transport is an important component of larval dispersal, and broad dispersal requires significant larval transport. Restricted dispersal, however, does not imply little larval transport (Figure 1). Further, processes and factors associated with the end of larval transport (i.e., settlement) also influence dispersal, including settlement behavior, distribution of suitable settlement sites, and refuge availability (Figure 2). Similarly, because spawning initiates larval dispersal, spawning time and location are important, as are factors influencing spawning, including season and synchronicity of spawning, age and condition of spawners, and fertilization success. In addition to the spatial dimensions inherent in larval transport, larval dispersal involves a survival probability, and thus food availability and predation are important. The highest mortality in marine populations occurs invasive species, and other phenomena (Cowen et al., 2006, this issue; Levin, 2006). By this definition, if the exchange is measured at the time of settlement, connectivity is essentially larval dispersal from one population to another (e.g., Webster et al., 2002). Not all settlers will survive, however, and survival may be influenced by larval experience. Thus, connectivity is frequently measured at some point after settlement, once settlers survive to enter, or recruit to, the juvenile population. Functionally, however, this point is somewhat arbitrary and differs among taxa. A more precise demographic milestone is reproduction. If settlers die without reproducing, dispersal is of questionable importance to population growth or spread of invasive species. In this contribution we differentiate between population connectivity, measured at the time of settlement, and reproductive population connectivity, defined as the dispersal of individu-

\section{The fundamental challenge in population connectivity studies is to determine the source populations of settling larvae and the settlement sites of dispersing larvae.}

during the early life stages, so mortality plays a large, but understudied, role in larval dispersal.

Population connectivity has been defined as the exchange of individuals among geographically separated subpopulations (see Cowen et al., this issue) and is thought to be a key process for population replenishment, genetics, spread of als among subpopulations that survive to reproduce. Reproductive population connectivity encompasses larval dispersal but is also influenced by postsettlement mortality (e.g., Hunt and Scheibling, 1997; Doherty et al., 2004), growth, and condition from settlement to successful reproduction. By the definition above, although dispersal of larvae 
that do not survive to reproduce can play a role in population and community ecology, their contributions to reproductive population connectivity are minimal (Figures 1 and 2).

\section{LARVAL TRANSPORT}

\section{Reconsideration of the}

Scales of Larval Transport

The term larval transport brings to mind small, passive larvae being moved throughout the ocean by meso- and large-scale physical processes (Johnson, 1939). This view has become a paradigm-larvae are released, transported by mesoscale processes, mixed in a larval pool, and then randomly recruited to juvenile or adult habitat (e.g., Roughgarden et al., 1988; Siegel et al., 2003). An increasing number of studies, however, conclude that a significant amount of self-recruitment occurs in marine populations (Jones et al., 2005; Almany et al., 2007). These conclusions are not in and of themselves surprising: a population is defined as a self-sustaining component of a species, and thus self-recruitment is a defining attribute of a population (Sinclair, 1988). What is surprising is the relatively small spatial scales over which self-recruitment has been observed. For example, despite a planktonic stage of 9-12 days, approximately $30 \%$ of settling panda clownfish self-recruited to an area of $0.5 \mathrm{~km}^{2}$ (Jones et al., 2005). The implication of this and similar observations, combined with recent modeling and genetic studies (Cowen et al., 2000; Gerlach et al., 2007)

JESÚS PINEDA (jpineda@whoi.edu) is Associate Scientist, Department of Biology, Woods Hole Oceanographic Institution, Woods Hole, MA, USA. JONATHAN

A. HARE is Research Marine Scientist, National Oceanic and Atmospheric Administration, National Marine Fisheries Service, Northeast Fisheries Service Center, Narragansett Laboratory, Narragansett, RI, USA. SU SPONAUGLE is Associate Professor, Marine Biology and Fisheries Division, Rosenstiel School of Marine and Atmospheric Science, University of Miami, Miami, FL, USA.

\section{BOX 1. VARIABILITY IN SPATIAL AND TEMPORAL SCALES OF LARVAL TRANSPORT}

The movement of larvae in internal bores is an example of the variety of spatial and temporal scales involved in larval transport. Larval accumulation at surface-propagating convergences is critical for effective transport in internal bore warm fronts, and the time scales of these convergences are from a few seconds to a few hours. On the other hand, water-column stratification, a seasonal phenomenon, modulates the energy of internal bores and therefore also impacts larval transport (Pineda and López, 2002). At even larger scales, stratification and internal bores are modulated by El Niño, an interannual phenomenon (Zimmerman and
Robertson, 1985). Thus, temporal scales relevant for understanding larval transport by internal tidal bores range from seconds to years. Other temporal scales important to internal tidal bore larval transport that are not depicted here include fortnightly periodicity ( 14.4 days), and the periodicity of coastally trapped waves (a few weeks; Pineda and López, 2002). In the literature, larval transport generally encompasses horizontal distances ranging from tens to hundreds of kilometers, a usage we follow in this contribution. 
and the constrained nearshore larval distributions of littoral species (Barnett and Jahn, 1987; Tapia and Pineda, 2007), is that the spatial scales of larval transport may be much smaller than previously recognized. These results indicate that small-scale and nearshore physical processes play an important role in larval transport (Kingsford, 1990; Willis and Oliver, 1990; Pineda, 1999).

\section{Nearshore, Coastal, and \\ Oceanic Currents}

Flows in nearshore, shallow environments, including the surf zone, are different from coastal and deep-ocean flows mainly because of the shoreline barrier, shallow depths, bathymetric features associated with the continental shelf, and nearshore inputs of freshwater. ${ }^{1}$ Moreover, flows in nearshore waters tend to be more complex than in the deep and coastal ocean because many processes operate there, including surface gravity waves, buoyancydriven flows, wind-forcing, surface and internal tides, large-amplitude internal waves and bores, and boundary-layer effects. These differences between nearshore and coastal/open ocean hydrodynamics are important for larval transport. The shoreline barrier serves as a topographic guide for coastally trapped waves and tends to steer flows in the alongshore direction (see Box 2). Tidal ellipses that tend to be isomorphic in the open ocean become compressed near the coast, and large-scale flows such as the Gulf Stream and the Humboldt Current flow parallel to the shoreline, not perpendicular. Freshwater runoff and large-scale currents running parallel to the coastline produce characteristic stratification in the nearshore, such as shallowing of the thermocline near the coastline in response to the California Current (Hickey, 1979) and the Florida Current/Gulf Stream (Leaman et al.,

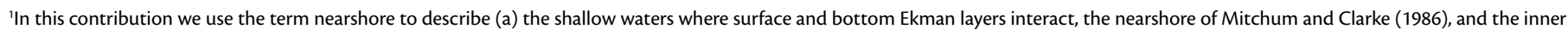
shelf of Lentz (1995), and (b) the surfzone, while the coastal region includes mid- and outer-shelf areas.
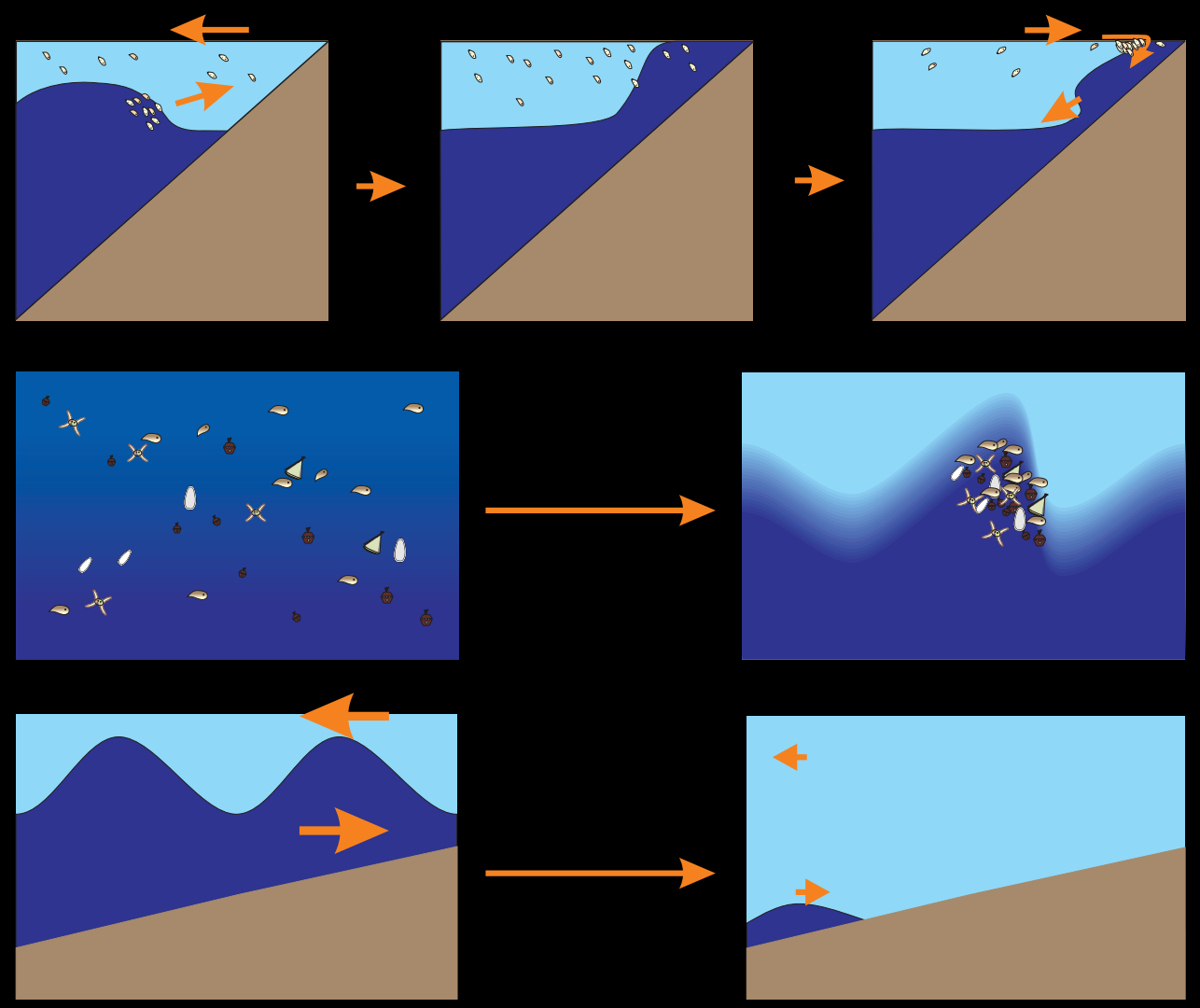
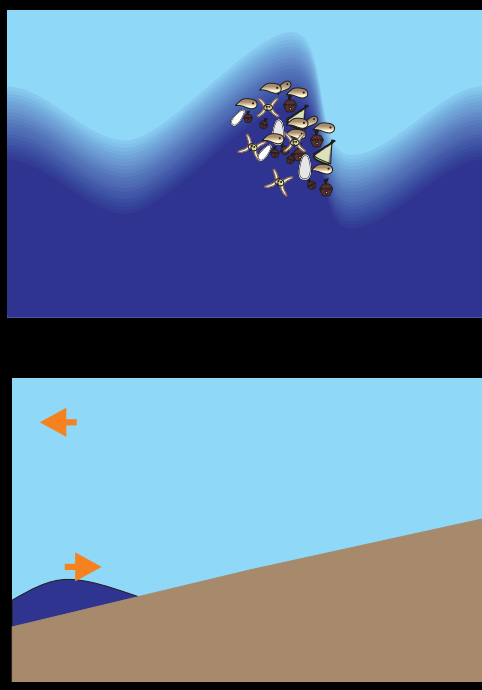

Accumulation in internal tidal bore warm fronts (seconds to hours)

Seasonal stratification (months)

\section{El Niño} (several years) 


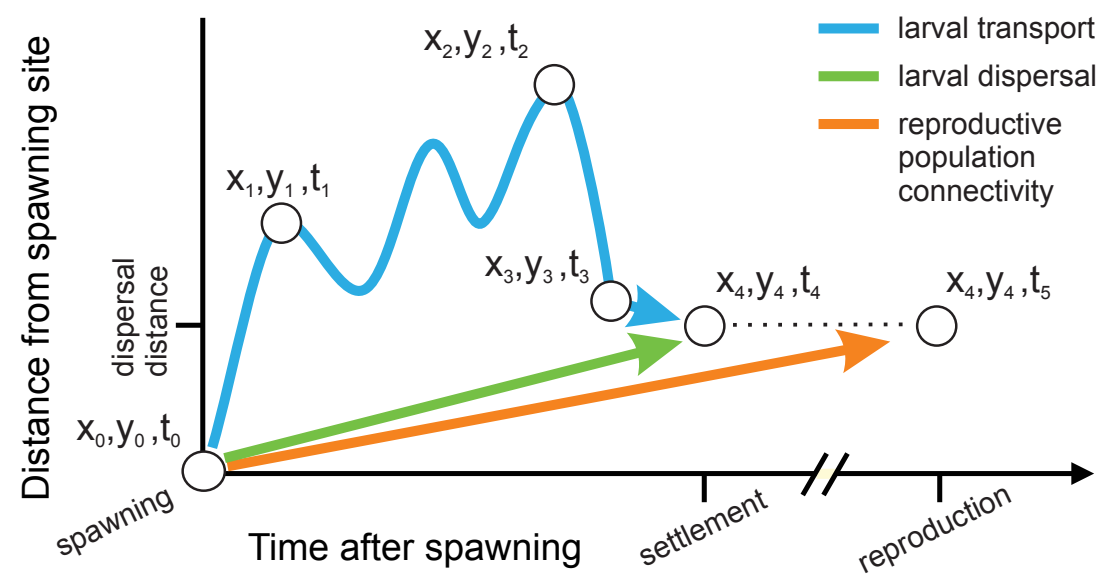

Figure 1. Relationship between the spatial and temporal components of larval transport, larval dispersal, and reproductive population connectivity for a sessile species. Survivorship is not depicted. Note that the sum of larval transport distances can be larger than the dispersal distance. White circles are locations in space with coordinates $x-y$ at times $t$. All locations are pelagic except $x_{0}, y_{0}$ and $x_{4}$ and $y_{4}$, which are benthic. Distance could also be represented in two dimensions (e.g., $x, y$ as cross- and alongshore axes.)

1989). Salinity (Thièbaut et al., 1992) and water-column stratification (Pineda and López, 2002) contribute to larval transport because sharper stratification in shallow waters (e.g., Hickey, 1979) allows larvae of coastal species to exploit vertically sheared flow to control horizontal distributions (Paris and Cowen, 2004), and internal motions such as internal tidal bores may transport larvae onshore. Surface waves that break near the shore produce some mass transport, and storm systems that originate in the deep ocean sometimes move onshore. Flows in the nearshore are broken by coastline topographic features such as bays and capes, resulting in complex flows with smaller spatial coherence (see discussion in Okubo, 1994). This is true for cross-shore coastal flows, whose coherence scales are much smaller than the alongshore coastal flows (Brink, 1999). The relative importance of these processes varies with depth and distance from the shoreline (e.g., Lentz et al., 1999; Largier, 2003).

\section{Modulation of Nearshore Cross-Shore Transport by Large-Scale Processes}

Clearly meso- and large-scale processes affect larval transport, and most studies emphasize these effects. Large-scale physical processes also influence the smaller-scale processes discussed above. Many large-scale circulation systems and processes, such as eastern and western boundary currents, El Niño, coastal upwelling, and coastally trapped waves, are energetic and coherent in the alongshore direction, but can also modulate smaller-scale processes in ways that enhance or suppress larval transport. For example, as pointed out above, the strength of the California Current determines the depth of the thermocline in shallow nearshore waters, with a stronger current resulting in a shallow ther- mocline. A shallow thermocline creates vertically sheared environments that may restrict larval transport for species with diel vertical migration; thus, interannual variability in the strength of these large-scale current systems might lead to variability in dispersal, an untested speculation. Consider the effects of coastal upwelling, El Niño, and coastally trapped waves on shallow water stratification and cross-shore transport along the west coasts of North and South America. The combination of strong coastal upwelling and El Niño produces weak nearshore stratification due to the upwelling of unstratified cold waters and the piling up of mixed surface warm waters in the nearshore (Simpson, 1984; Zimmerman and Robertson, 1985). Both upwelling and El Niño result in decreased watercolumn stratification, suppressing the shallowing of the thermocline by the internal tide and the internal tidal bores, which, in turn, may result in decreased onshore larval transport (recent work of author Pineda and Manuel López, Centro de Investigación Cientifica y de Educación Superior de Ensenada). In contrast, coastally trapped waves produce a transient, small drop in sea level that is compensated by a large uplifting of the nearshore thermocline. This results in the shallowing of the thermocline by the internal tide and larval transport by internal bore warm fronts (Pineda and López, 2002).

\section{Small-Scale Processes and Event-Type Larval Transport} Spatial and temporal scales are linked in the ocean (Stommel, 1963), so the importance of small-spatial-scale processes underscores the significance of 
small-temporal-scale processes to larval transport. Moreover, meso- and largescale processes can exhibit small-temporal-scale variability (Stommel, 1963) and be episodic (e.g., hurricanes). Larval settlement from the plankton for many marine organisms is episodic, and it is not uncommon to have the majority of a season's settlement occur in a handful of days (Forward et al., 2004; Sponaugle et al., 2005). Even though settlement records imply transport events and are often correlated with various physical factors, the observation of eventdriven larval transport remains elusive. Similarly, larval distributions are often used to infer transport and the influence of events (e.g., the occurrence of an eddy; Limouzy-Paris et al., 1997), but few studies have measured the movement of larvae in the water over time by event-type processes. When larval distributions are sampled repeatedly over time, they offer excellent views of the processes involved in larval transport (Pepin and Helbig, 1997; Natunewicz and Epifanio, 2001), but due to sampling limitations, such studies are rarely able to observe the influence of smaller-scale processes. Examining the effect of events on transport is more straightforward in a modeling context-a well-modeled example is the effect of winddriven events on settlement (Garvine et al., 1997; Brown et al., 2004)—but most circulation models do not capture smaller-scale physical processes, frontogenesis, frontal convergence and divergence, intrusions, internal waves, and topographic effects, particularly in the nearshore.

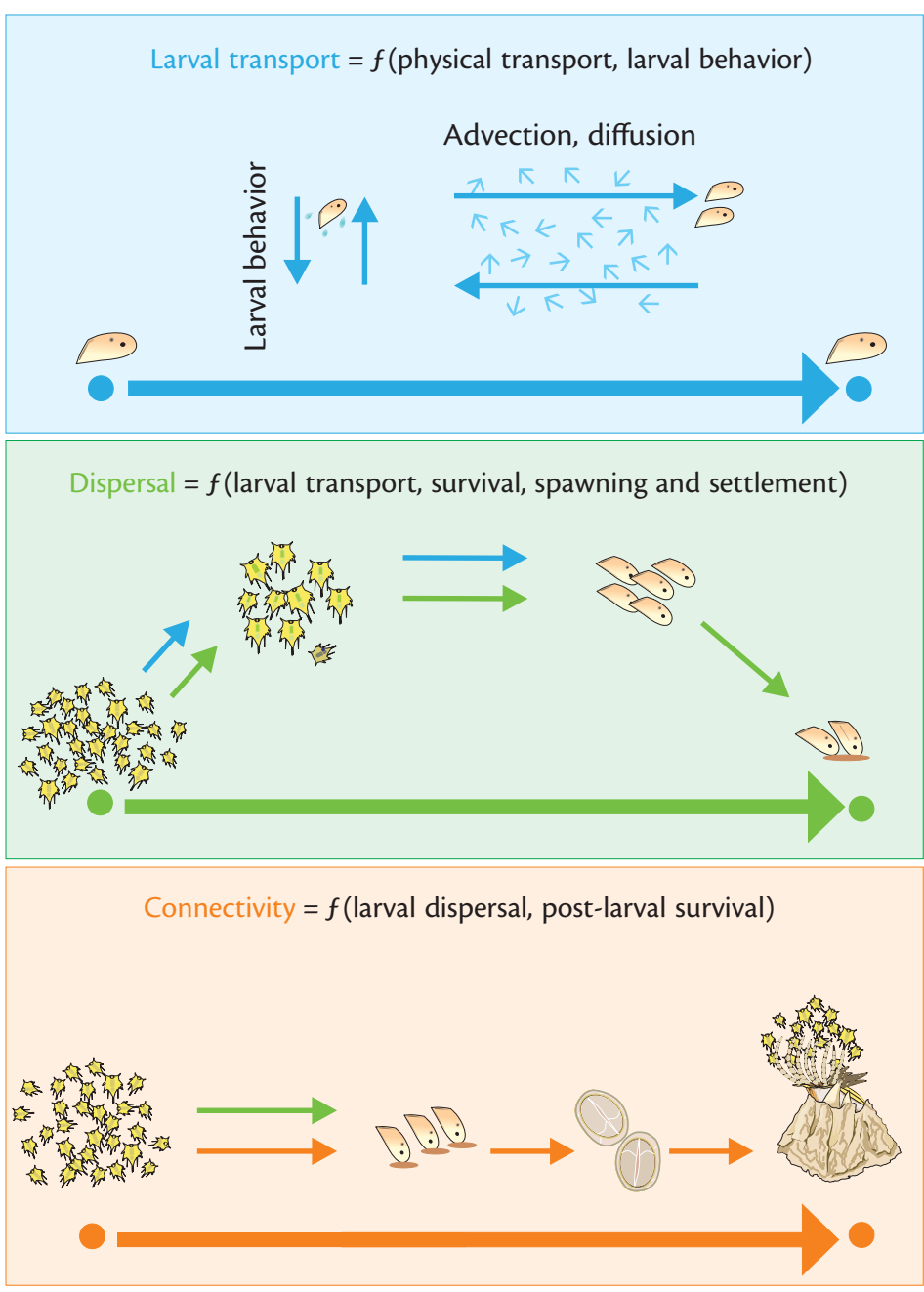

Figure 2. The concepts of larval transport, larval dispersal, and reproductive population connectivity. Colors of arrows distinguish each concept. For example, the green arrow in the connectivity box means dispersal is involved in reproductive population connectivity.

\section{Behavior and Larval Transport}

As our appreciation of small-scale physical processes grows, so does our appreciation for the role of larval behavior in influencing larval transport. For many years, larvae were considered planktonic, that is, moving at the whim of ocean currents but using feeding and predator avoidance behaviors that resulted in small-scale (millimeters to centimeters) movements (Blaxter, 1969). The view of passive larvae gave way to the con- cept that vertical swimming behavior, changes in buoyancy, and ontogenetic changes in vertical position influence the horizontal movement of larvae; this view was adopted early in estuarine and coastal lagoon systems (Nelson, 1912; Pritchard, 1953; Bousfield, 1955) and later in shelf and open-ocean systems (Kelly et al., 1982; Cowen et al., 1993). Additionally, the influence of larval settlement behavior on the specific location of settlement, at scales of meters to tens 
of meters, was recognized as important (e.g., Crisp, 1976; Raimondi, 1991).

More recent research shows that larvae also have horizontal swimming capabilities that improve with development (see review by Leis, 2006). For example, larvae of a damselfish swam continuously for 39 hours without food, covering a distance equivalent to $19 \mathrm{~km}$ (Stobutzki, 1997). Similarly, larval lobsters and early pelagic stages of cephalopods are good swimmers (Villanueva et al., 1996; Jeffs and Holland, 2000). In combination with the capability to swim vertically and horizontally, larvae of both invertebrates and vertebrates can orient and potentially navigate over short (meter-to-kilometer) to long (10-to-100-km) distances, using light, sound, smell, and possibly magnetism, electric fields, and wave swell (e.g., Kingsford et al., 2002; Gerlach et al., 2007). Clearly, larvae are complex and capable organisms that develop the ability to feed, avoid predation, and move within the pelagic environment. Thus, in the equation of larval transport, behavior plays an equally important role as advection and diffusion.

\section{LARVAL TRANSPORT:}

\section{RESEARCH NEEDS}

Identification of Nearshore Larval Transport Mechanisms

Knowledge of larval transport in nearshore environments is very limited. Major drawbacks include lack of rigorous knowledge of the suspected physical mechanisms involved in larval transport, and ignorance of other potential transport mechanisms (see Cowen, 2002, for a review). Physical mechanisms that could affect transport include surface gravity waves (Monismith and Fong, 2004), submeso- and mesoscale eddies (Bassin et al., 2005; Sponaugle et al., 2005), barotropic tidal currents (Hare et al., 2005; Queiroga et al., 2006), and cross-shore winds (Tapia et al., 2004).

Some proposed mechanisms have not been tested rigorously in field conditions. Moreover, the logistical difficulty of studying transport sometimes can push researchers to use weak inferential approaches, such as inferring larval transport mechanisms from settlement data (Pineda, 2000; Queiroga et al.,

BOX 2. ALONG-AND CROSS-SHORE PHYSICAL TRANSPORT PROCESSES

Larval transport in nearshore and shelf species is often split into crossand alongshore components (e.g., Hare et al., 1999; Ma and Grassle, 2005). This distinction follows a convention in coastal physical oceanography and is convenient because cross- and alongshore hydrodynamic processes have different temporal and spatial scales (Winant, 1983), different physical processes dominate cross- and alongshore transport (e.g., Winant and Bratkovich, 1981), and momentum balances in these two axes are accounted for by different terms (e.g., Lentz et al., 1999). Also, plankton patches have widely different dimensions in the two axes (Mullin, 1993). Because the strongest gradients in water properties and ecological variables are in the cross-shore dimension, transport on this axis has a disproportionately large effect on the distribution of larvae. For nearshore species whose later developmental stages move progressively offshore with time, such as the southern California barnacle nauplii (Tapia and Pineda, 2007), cross-shore transport is the most critical process, as older larvae tend to be farther away from the shore and must return nearshore to settle and reproduce. Similarly, for species that move offshore to spawn but have nearshore settlement habitats, such

as Atlantic menhaden (Quinlan et al., 1999), larvae must move onshore to recruit to juvenile habitats. Although cross-shelf transport is often emphasized in studies of larval transport, it is obvious that alongshore processes also play a role (Hare et al., 1999), particularly in population connectivity. Nearshore and coastal marine populations are generally arrayed along coasts, and the alongshore movement of larvae between these populations can keep these geographically isolated populations

\section{connected.}


2006). The lure of mesoscale processes and satellite oceanography has proved irresistible for some shallow-water ecologists, resulting in an overemphasis on explanations based on mesoscale processes while disregarding nearshore processes and mechanisms that cannot be studied remotely. Unambiguous identification of the mechanisms of larval transport is rare, and testing alternative explanations is almost unheard of. Thus, there is a serious need to follow up some of these weakly founded hypotheses with rigorous tests. With limited knowledge of nearshore larval transport, it seems that assessing the relative contributions of various physical transport mechanisms in larval transport for a given case study is, so far, only a utopian hope. The field will be mature when such a study can be proposed and accomplished.

Understanding the role of small-scale processes in larval transport is also limited by modeling capabilities. Large-scale and mesoscale models forced by winds and the surface tide are now commonplace (see Werner et al., this issue). The spatial resolution of these models is increasing and extending into nearshore areas (e.g., Chen et al., 2006). Decreased grid size, however, is only one aspect of resolving smaller-scale processes. Smallscale processes, such as surface waves, internal waves, and propagating convergences, need to be included. Currently, no numerical model appears capable of simultaneously resolving Lagrangian transport caused by, for example, shallowing internal tides, sea breeze, largeamplitude internal waves, and surface gravity waves. Further, accurately modeling larval transport will require embedding these small-scale processes in larger-scale models, thereby capturing the large-scale aspects of larval transport, the modulation of small-scale processes by large-scale forcing, and the very small-scale processes (e.g., turbulence) where larval swimming capabilities and behavior become overly important (see discussion in Metaxas, 2001). Even modeling a single, relatively straightforward process, such as the accumulation of particles in gravity currents, can be extremely complex (e.g., Scotti and Pineda, 2007). Thus, using numerical models for inferring larval transport when poorly studied processes may be important, or where the physical forcing is unknown, is dire. On the other hand, it is clear that numerical models are powerful tools in settings where processes are well known and in cases where field hydrodynamics are well simulated by the model (e.g., Reyns et al., 2006). Thus, we suggest that bottlenecks in understanding larval transport are less related to numerical modeling than to the mechanistic knowledge of larval transport.

\section{Challenges of Adaptive Sampling}

It is unclear how much larval transport occurs during episodic events and how much occurs during "mean" conditions. Sharp peaks in settlement time series and studies of larval transport by wind and internal motions suggest that transport can be sporadic, larvae extremely patchy, or both (see Pineda, 2000, for discussion). Time-series measurements of relevant hydrodynamics and larval distributions during larval transport are of limited use when measurements cannot be taken with the necessary frequency and spatial resolution to describe the processes with sufficient detail. Furthermore, surveys by research vessels diligently planned in advance do not guarantee that larval-transport events will happen during the surveys. Adaptive sampling, defined as sampling in response to an event, is a solution to these dilemmas; it has been used successfully to sample hydrodynamics and larval distributions during transport by internal tidal bores (Pineda, 1994, 1999). Adaptive sampling is challenging, however, because it is hypothesis based; sampling is initiated in response to a real-time change in a time-dependent variable, such as temperature or wind direction, that is integral to the hypothesized larval transport mechanism. Adaptive sampling is therefore a stringent hypothesis test, because if larval transport does not occur as expected, the hypothesis is rejected. Adaptive sampling is also logistically difficult. If the events are sporadic, and the sampling is shipboard, adaptive sampling requires having a vessel and crew on standby ready to sample for long periods, an expensive prospect for anxious researchers. Conceivably, remote sampling systems initiated in response to events could be constructed with off-the-shelf gear and new technologies currently under development such as in situ molecular detection of larvae (e.g., Goffredi et al., 2006). Thus, similar to the limitations in modeling larval transport, adaptive sampling is limited in part by technology and in part by the development of testable, mechanistic hypotheses.

Breaking the Behavioral Black Box The incorporation of larval behavior fully into the larval transport equation requires several important advances. 
First, hypotheses on the role of behavior in transport need to be developed and tested. Colby (1988) argued that passive advection and diffusion should be the null hypothesis for studies of larval transport. In an early example of this approach, Woods and Hargis (1971) compared the distribution of coal particles with that of similarly sized oyster larvae and concluded that larvae were not being transported passively. A study on ascidian tadpole larvae found that dispersal distance was shorter in swimming larvae than in nonswimming individuals of similar size and shape (Bingham and Young, 1991). Similarly, Arnold et al. (2005) followed a cohort of larval hard clams and found their distribution differed from dye distributions and from modeled distributions based on passive particles. There are other examples of the use of a hypothesis-testing approach for evaluating the processes that affect larval transport (e.g., Hare et al., 2002). This approach should be expanded to take advantage of advances in modeling as well as in field and laboratory studies. Behavioral hypotheses from laboratory studies are attractive because quantification of hydrodynamics and behavior is feasible, but these hypotheses should be tested in field conditions, and vice versa.

Second, the incorporation of behaviors into models of transport needs to be rule-based rather than deterministic, and individual variability should be considered. Most transport models that include larval behavior use population-level descriptions of distributions or swimming speeds and apply them to particles released in the model (Hare et al., 1999). Another approach is to provide a set of behavioral rules that attempt to capture the trade-offs between feeding and predation; these rules result in vertical (and potentially horizontal) responses to various cues (Titelman and Fiksen, 2004; Fiksen et al., in press). Although the importance of time-dependent behaviors, such as diel, tidal, and ontogenetic, is well recognized, little is known about "adaptive" behavior on scales of seconds to minutes, where larvae might respond to transient physical and biological features. We know that larvae respond behaviorally to a number of factors, such as time of day, light, temperature, turbulence, pressure, and food availability, and that some of these responses influence transport, but only a few behaviors facilitating transport have been identified (e.g., Boehlert and Mundy, 1988; DiBacco et al., 2001). For example, field observations, modeling, and laboratory experiments imply that "swimming up" behaviors in response to transient downwelling flows in propagating features determine efficient larval transport (Pineda, 1999; Scotti and Pineda, 2007). To incorporate our understanding of behavior into rule-based models will require a hypothesis-based approach. Without hypotheses, we run the risk of evaluating the effect of multiple irrelevant behavioral scenarios on larval transport. This rule-based approach coupled with more studies on adaptive behavior and well-developed biophysical, individual-based models (e.g., Lough et al., 2005, and recent observations of Claudio DiBacco of Bedford Institute of Oceanography, author Pineda, and Karl Helfrich of WHOI), will greatly advance our understanding of the combined roles of advection, diffusion, and larval behavior.
Third, most research has focused on how larval behavior affects advection, but the influence of behavior on diffusion requires more emphasis. Using an advection-diffusion-mortality model, Cowen et al. (2000) estimate that successful larval transport to coral reef habitats diminishes sharply when diffusion rates increase from 0 to $100 \mathrm{~m}^{2} \mathrm{~s}^{-1}$ (the latter is a typical diffusion rate used in larval transport studies; see also Okubo, 1994). However, the assumption that larvae diffuse passively in the marine environment likely does not hold, particularly for older larval stages. Peaks in settlement must result from highdensity patches of larvae reaching adult habitats, and these coherent patches run counter to hypothesized diffusion. Natunewicz and Epifanio (2001) followed discrete patches of crab larvae for up to six days and hypothesized that associative swimming behaviors might be responsible for patch maintenance. A U-shaped patchiness-at-age function has been described for the larval stages of several fish species, and this shape has been interpreted as initial diffusion with subsequent schooling (Matsuura and Hewitt, 1995). In addition, larvae may remain in thin layers of food (Lasker, 1975) and reduce their diffusion owing to vertical differences in flow (shear diffusion). Larvae can also accumulate at upwelling and downwelling fronts by swimming into the current (e.g., Franks, 1992; Metaxas, 2001), thereby reducing diffusion. Thus, small-scale vertical and horizontal larval behavioral responses may limit diffusion and greatly affect larval transport. Consequently, the use of advection-diffusion models to understand larval transport requires great 
care. For example, Hill (1991) underscored the limitations of an advectiondiffusion-mortality model in cases when active vertical positioning of larvae was expected, and Okubo (1994) warned that a horizontal diffusive model would not work in settings with strong convergent flows, a widespread phenomenon in coastal and nearshore settings.

\section{LARVAL DISPERSAL}

Defining Dispersal Kernels

Most attempts to describe dispersal kernels have emphasized larval transport (e.g., Botsford et al., 1994), but other processes such as spawning, settlement, pelagic larval duration, and survival also influence larval dispersal (Edwards et al., in press). Many marine species release their offspring at specific locations and times, using specific behaviors. For example, relatively sedentary bluehead wrasse spawn daily at particular reef spawning sites that have been used for years (Warner, 1988). Similarly, several fish species spawn in circular motions that may create hydrodynamic vortexes (Okubo, 1988; Heyman et al., 2005). The influence of these small-scale events on larval dispersal over periods of weeks is unknown. On a larger scale, a number of motile species, including snappers, herring, and blue crabs, move to particular locations for spawning (Carr et al., 2004; Heyman et al., 2005). In the temporal domain, many coral species participate in annual mass spawning events, with more than $60 \%$ of species spawning over the course of several days (Babcock et al., 1994), and crabs and barnacles tend to release their larvae at certain phases of the tide or the day (Morgan, 1995; Macho et al., 2005). While such spawn- ing behaviors have long been thought to maximize larval survival (e.g., Hughes et al., 2000), the overall effect of localized and punctuated spawning on larval dispersal is unclear.

Moreover, where individuals end their planktonic stage is also an important
10-15 km of known habitat have successfully settled (Hare et al., 1999; Paris et al., 2005). How larvae transverse these last $10 \mathrm{~km}$ is unknown largely because of the exclusion of smaller-scale processes in models and the inability to include realistic behaviors (see above).

\section{...all the research needs identified under the larval transport and dispersal sections sum together as research needs for \\ population connectivity.}

component of larval dispersal. Larval durations of some species are fixed while others are flexible (Pechenik, 1986; Cowen, 1991). Some species have very narrow habitat requirements for the continuation of the life cycle, such as river mouths on isolated oceanic islands for some gobies, wave-beaten rocky points for gooseneck barnacles, and specific species of anemones for some reef fish (Radtke et al., 1988; Cruz, 2000; Jones et al., 2005). Other species have broad habitat requirements such as eurytopic Pachygrapsus crabs (Hiatt, 1948) and flounders of the genus Etropus (Walsh et al., 2006). For most species, only a subset of locations will support the continuation of the life cycle; these locations must be reached within the time window of possible settlement. Understanding these habitat and time constraints will be necessary to observe and model dispersal kernels. A number of models have included such considerations at a relatively large scale, for example, assuming modeled larvae that arrive within
The dispersal kernel also is dependent on larval mortality. Most studies of larval dispersal, however, either do not consider larval mortality (Hare et al., 1999), consider spatially homogenous mortality (Cowen et al., 2000), or assume low mortality (Gaylord and Gaines, 2000). Modeling studies that assume low mortalities should be reconsidered in light of observed higher mortalities (e.g., Rumrill, 1990); use of high mortalities in dispersal models frequently yields lower maximum dispersal estimates than those obtained assuming low mortality (Cowen et al., 2000; Ellien et al., 2004; Tapia and Pineda, 2007). Differential survival of larvae during transport contributes to defining the dispersal kernel in potentially numerous species-specific ways. The ecological literature is rich with examples and models in which the role of spatial heterogeneity in mortality shapes subsequent patterns in abundance, distribution, and demographics. These concepts, however, have yet to be applied to mortality in pelagic early life 
stages. It is also clear that not all larvae are equal, and the range of traits will result in selective survival (see later section on Population Connectivity).

Larval duration also influences survival probability. Pelagic larval duration (PLD) must be correlated with the dispersal kernel for the simple reason that species with short PLD must have reduced larval transport and relatively "short" dispersal kernels; PLD is a constraining variable for dispersal. In contrast, long PLDs do not necessarily yield broad dispersal kernels, as larval behavior breaks the direct-proportional relationship between PLD and dispersal distance, both for fish and invertebrates (Sponaugle et al., 2002). Of course, long PLD yields higher cumulative mortalities than short PLD when everything else is equal (i.e., same daily mortality for species with short and long PLD; see Hare and Cowen, 1997). It is also unclear how variables influencing PLD, such as temperature and food (Scheltema and Williams, 1982), may influence the dispersal kernel (see O'Connor et al., 2007, for model predictions). Thus, the relationship between PLD and dispersal is ambiguous except for species with very short larval durations (see discussion in Sponaugle et al., 2002).

\section{Dispersal Estimates in the \\ Coastal Ocean}

Given the complexity of larval dispersal, it is not surprising that measurement of a dispersal kernel in the marine environment is extraordinarily rare (Shanks et al., 2003). Gerrodette (1981) measured the dispersal of planula larvae from adults in a temperate solitary coral and found that mean dispersal distance from the parent was $<50 \mathrm{~cm}$. Similar work with ascidians quantified dispersal from spawning to settlement, but the pelagic stage of ascidians is short (hours), larvae are large (millimeters), and mortality is low (<90\%) (Olson and McPherson, 1987), making it possible to follow individuals from the beginning to the end of the pelagic stage (see also Bingham and Young, 1991). Work on an isolated reef indicated that most acroporid and pocilloporid corals recruited in experimental moorings within $300 \mathrm{~m}$ from the reef, and that spat mortality decreased with distance from the reef (Sammarco and Andrews, 1989). Several studies followed patches of more typical marine larvae

\section{Eventually, long-term, labor-intensive studies}

will be needed to increase our understanding

of reproductive population connectivity of

longer-lived mobile species.

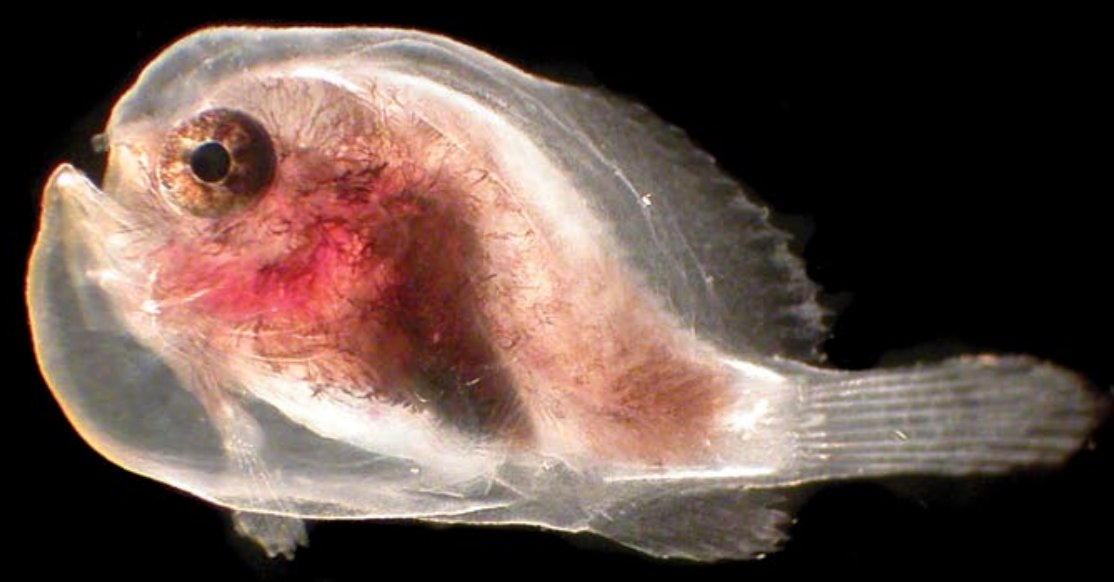


(PLD of weeks, size $<1-10 \mathrm{~mm}$, and high mortality), but these efforts are not true measures of larval dispersal because the spawning and ending locations were inferred (Pepin and Helbig, 1997; Natunewicz and Epifanio, 2001; Paris and Cowen, 2004). Other studies marked spawned eggs and then collected offspring at the end of their planktonic stage (Jones et al., 2005; Almany et al., 2007); these studies provide a partial measure, but not a complete description, of the dispersal kernel because all potential ending locations could not be sampled. Although dispersal kernels will eventually be fully quantified for some species in some systems, the measurement of these probability distributions in the marine environment will remain extremely rare.

It is easier to obtain dispersal kernels with models than with field measurements. Some models consider simplified situations using advection-diffusion models. More complex numerical circulation models coupled with Lagrangian particle-tracking algorithms follow particles released at multiple locations and multiple times and have proven instrumental in estimating dispersal kernels in the marine environment (Cowen et al., 2000; see also Werner et al., this issue). Edwards et al. (in press) used a fully orthogonal approach to examine the effects of different factors on generic two-dimensional dispersal kernels estimated from a three-dimensional circulation model of the Southeast United States shelf. This study found that time and place of initial release were most important in determining the position of the dispersal kernel, and that dispersion and PLD were most critical in determining the spread of the dispersal kernel.
Larval behavior was not as important, but horizontal swimming behavior was not included and depth-stratified currents were minimal through most of the modeling domain, limiting the effect of different vertical positions.

\section{LARVAL DISPERSAL:}

\section{RESEARCH NEEDS}

\section{Field Observations of Dispersal}

The paradigm of broad dispersal of fish and invertebrate larvae is giving way to the notion of restricted dispersal, mainly because of studies finding: (1) unexpected high levels of selfrecruitment, (2) high larval mortality rates, and (3) restricted scales of larval transport (see above). Still, the dominant scales of dispersal are not known. Solid empirical estimates of dispersal are needed to guide field and numerical modeling studies to address questions such as: What regions of the ocean should researchers focus on? What processes must be included in the models? Studying dispersal is challenging, and for fish and invertebrate species with long and typical larval durations (i.e., about four weeks for temperate invertebrates; Levin and Bridges, 1995), knowledge will be gained incrementally by using multiple approaches, including: (1) empirical estimates of larval origin, such as natural and artificial tags and genetic distance and structure, (2) a mechanistic understanding of larval transport,

(3) assessment of how the space and time of spawning and settlement influence dispersal, (4) trophodynamic studies to address the influence of pelagic patchiness and structure on the larval journey from spawning to settlement, and (5) improved mortality estimates in dis- persal models in locations where physical processes are well known.

When empirical estimates of dispersal are obtained, it is crucial that they be used to test the assumptions and hypotheses resulting from both simple and complex models. Robust measurements of dispersal will be rare and opportunities to evaluate and test models must not be lost. In this way, the skill of models can be assessed and improved through an iterative process of observation and modeling, and the resulting dispersal kernels can be part of larger studies of connectivity with increasing confidence. Although the challenges are immense, we emphasize that solid empirical estimates of dispersal are necessary to guide further field studies and numerical modeling; theoretical developments and modeling of spatial population processes and connectivity may be futile unless we gain more observationally based knowledge of larval dispersal.

\section{POPULATION CONNECTIVITY The Concept of Population Connectivity}

A mechanistic understanding of larval dispersal is sufficient for determining population connectivity at time of settlement. Knowledge of population connectivity at the time of settlement or shortly thereafter may be adequate for some objectives because subadult individuals use resources, interact with adults and other members of the community and in some instances, sustain fisheries. Reproductive population connectivity, on the other hand, is the exchange of individuals that eventually reproduce. Accordingly, for benthic marine species, it is not only a function of larval dispersal 
(including survivorship of larvae during transit), but also of post-settlement and juvenile survival to the point of reproduction (Figures 1 and 2). Reproductive population connectivity can be expressed as the number of individuals from site a and population $\mathrm{A}$ that disperse to site $\mathrm{b}$ containing population $\mathrm{B}$ and reproduce there per unit time. Thus, during development to the adult stage (which varies greatly among species, from days to multiple years), juveniles must survive, grow, mature, and reproduce. As characteristics of settlers are often variable and those surviving to reproduce may not be a random sample of the settlers, simply tracking larval trajectories from spawning to settlement is insufficient to quantify reproductive population connectivity. The remainder of this discussion considers the ecological processes contributing to reproductive population connectivity.

For a population to be ecologically sustained, a minimum number of offspring must mature and reproduce over time intervals dictated by species' longevity. Identifying this number is essential to parameterize population models, but an equally important consideration is the composition of the survivors that make up this number: What are the characteristics of dispersers that lead to successful recruitment? Which of those recruits will then survive to reproduce? Recent evidence points to important influences of spawning patterns, maternal effects, and pelagic experience on larval size, growth, condition, and survival. Furthermore, many of these larval traits "carry over" and influence juvenile survival. However, comparatively little is known about the linkages between these early life phenomena and adult survival and reproduction.
Variation in Larval Traits and Survival During the Pelagic Stage Most larvae exhibit variation in early life history $(\mathrm{ELH})$ traits, such as size at a given age and growth rate. This variation can be introduced as early as the egg stage, when differential size, age, condition, or stress level of the mother can influence quality of the spawned eggs (Berkeley et al., 2004; McCormick, 2006). Larval encounter with variable pelagic environments also influences larval growth and survival. Water temperature plays a central role in regulating metabolism and growth (Houde, 1989), with larvae in different temperatures exhibiting variable ELH traits (Meekan et al., 2003; Sponaugle et al., 2006). Sustained growth requires adequate food; therefore, variable access to food also affects larval traits and survival. Transit across nutrient-poor open oceans may be particularly difficult for species with high growth rates. Access to food and avoidance of predation or other developmental conditions may be related to the timing of spawning, such that particular "windows" of time result in higher larval survivorship (Cushing, 1990; Baumann et al., 2006). Encounter with oceanographic features such as fronts or mesoscale eddies can also influence food supply and exposure to predators (Grimes and Kingsford, 1996; Sponaugle and Pinkard, 2004). Thus, a complex oceanographic environment coupled with variable egg quality at spawning results in a pool of larvae with variable traits (Jarrett, 2003; Lee et al., 2006; Sponaugle and Grorud-Colvert, 2006).

Survival of pelagic larvae is typically nonrandom and proceeds according to three general concepts of the "growth- mortality hypotheses" (reviewed in Anderson, 1988). Theoretically, survivors should be those larvae that are larger at a given age ("bigger is better" hypothesis; Miller et al., 1988), grow faster ("growthrate" hypothesis; Bailey and Houde, 1989), and/or move through an early stage more rapidly ("stage-duration" hypothesis; Anderson, 1988). Larvae of a diversity of marine fish (e.g., Meekan and Fortier, 1996; Hare and Cowen, 1997; Meekan et al., 2006) appear to adhere (to varying degrees) to aspects of these overarching concepts. Differential survival of larvae due to their pelagic experience and ELH traits can influence the magnitude of larval settlement pulses. Variation in the magnitude of settlement events has been related to variable larval growth throughout or during particular periods of larval life (e.g., Bergenius et al., 2002; Jenkins and King, 2006; Sponaugle et al., 2006)

\section{Influence of Larval Traits on} Juvenile Survival

Settlement of larvae to the benthos is a risky event plagued with high levels of predation mortality (e.g., Hunt and Scheibling, 1997; Doherty et al., 2004); thus, additional selective loss typically occurs during this period. Most marine species undergo a metamorphosis between the larval and juvenile stages as they move between radically different environments. While metamorphosis enables closer adaptation to stage-specific environments (Wilbur, 1980), larval history is not erased and accompanies this transition (Pechenik et al., 1998). Importantly, recent studies have begun linking these two stages and investigating how larval traits influence juvenile sur- 
vival. Traits exhibited by settling larvae as a consequence of pelagic constraints and selective pressures have the potential to "carry over" and influence survival of juveniles. For example, larval growth, size, and condition influence the survivorship of juvenile sponges, molluscs, barnacles, bryozoans, and fishes (e.g., Searcy and Sponaugle, 2001; Pechenik et al., 2002; Jarrett, 2003; McCormick and Hoey, 2004; Phillips, 2004; Marshall et al., 2006; Sponaugle and Grorud-Colvert, 2006). The potential exists for some traits that are advantageous to larvae to become subsequently detrimental to juveniles or vice versa. For example, crab zoeae reared at reduced salinities suffer higher mortality as larvae, but metamorphose into larger juveniles (Giménez and Anger, 2003), and a short pelagic larval duration enables fish larvae to escape the predation in the plankton, but results in smaller settlers (e.g., Sponaugle et al. 2006), which in some cases may be more susceptible to predation (Anderson, 1988). Most studies have focused on consequences to juveniles and somewhat less on the trade offs associated with conflicting constraints in complex life histories.

\section{Survivorship Beyond the Juvenile Stage}

Although events during larval life can play an important role in early juvenile survival, much less is known about how these traits are carried through or lost from individuals that survive to reproduce. Studies on larval dispersal or population connectivity typically define recruitment as entry into the juvenile population, not to the adult population. Thus, settlers are tracked at most to the point of settlement or through the

first few days or weeks as juveniles. We know little about the settlers that eventually survive to reproduce. It is generally substantially more time-consuming and logistically challenging to track cohorts of settlers all the way to reproduction. A few recent studies have had some success following species that mature rapidly.

\section{...simply reaching a settlement site does not guarantee that larvae will possess the necessary traits to survive to reproduce.}

Pineda et al. (2006) sampled barnacles that settled over an 89-day period until they reproduced 11 months later and found that survivors settled during a narrow 21-day "recruitment window." Meekan et al. (2006) tracked a single cohort of a fast-growing coastal fish and found that despite strong selective loss during early stages, there was no additional selective mortality between the juvenile and adult stages. For bryozoans in an experimental manipulation, however, adults that were larger as larvae had higher survival rates and produced larger larvae themselves than those that were smaller as larvae, although delaying metamorphosis erased this relationship (Marshall and Keough, 2006). Optimal traits may vary with the environment encountered by the larval, juvenile, or adult stages, as evident for a snail (Moran and Emlet, 2001) and colonial ascidian (Marshall et al., 2006). Thus, traits obtained during early stages have the potential for long-term effects on later stages, but many complex interrelation-
POPULATION CONNECTIVITY: RESEARCH NEEDS

The fundamental challenge in population connectivity studies is to determine the source populations of settling larvae and the settlement sites of dispersing larvae. In short, all the research needs identified under the larval transport and dispersal sections sum together as research needs for population connectivity. In addition, there is a need to link maternal effects and larval processes to early juvenile survival and, in the case of reproductive population connectivity, to the point of reproduction. Because reproductive population connectivity per se is defined as the exchange of individuals that eventually reproduce, tracking dispersing larvae to the point of settlement or juvenile recruitment, while important for some purposes, is functionally insufficient. New efforts to track settlers to reproduction will initially advance with shorter-lived sessile species. Eventually, long-term, labor-intensive studies will be needed to increase our understanding 
of reproductive population connectivity of longer-lived mobile species. There is a rich history of marine ecological work examining the relative importance of recruitment versus density-dependent, post-settlement processes in structuring benthic populations (Caley et al., 1996), but we need to move beyond numeri- if settlers that survive to reproduction are only spawned at time $t$ and site $x, y$, or if successful individuals only settle in recruitment windows coinciding with physical-transport processes $p$ and feeding and prey environments $e$, the vast parameter space that potentially affects pelagic eggs and larvae, and vexes

\section{Real measures of reproductive population}

\section{connectivity require an understanding of}

who is surviving to reproduce and why.

cal responses and refine the question to focus on trait-based ecological linkages among all stages. Real measures of reproductive population connectivity require an understanding of who is surviving to reproduce and why.

As there is ample evidence that larval growth and condition can influence performance in later stages, from a practical point of view we need more reliable measures of condition. The coarsest measures of condition often use size as a proxy (e.g., many invertebrates), while others measure organic (Jarrett, 2003) or lipid content (Hentschel and Emlet, 2000), RNA/DNA ratios (Suthers et al., 1996; Lee et al., 2006), or (for fishes) otolith-based measures (e.g., Sponaugle et al., 2006), all of which have some limitations. As new genomic techniques are developed, perhaps new measures of performance can be incorporated into both observational and manipulative studies.

Finally, focusing on the individuals that survive to reproduce may guide larval transport and dispersal studies; researchers, may be effectively reduced to a more manageable set.

\section{ACKNOWLEDGEMENTS}

We thank the National Oceanic and Atmospheric Administration, the National Science Foundation, and the Woods Hole Oceanographic Institution for supporting our work, and John Manderson, David Mountain, Nathalie Reyns, Vicke Starczak, Fabián Tapia, Simon Thorrold, and an anonymous reviewer for constructive criticisms. 정

\section{REFERENCES}

Almany, G.R., M.L. Berumen, S.R. Thorrold, S. Planes, and G.F. Jones. 2007. Local replenishment of coral reef fish populations in a Marine Reserve. Science 316:742-744.

Anderson, J.T. 1988. A review of size dependent survival during pre-recruitment stages of fishes in relation to recruitment. Journal of Northwest Atlantic Fishery Science 8:55-66.

Arnold, W.S., G.L. Hitchcock, M.E. Frischer, R. Wanninkhof, and Y.P. Sheng. 2005. Dispersal of an introduced larval cohort in a coastal lagoon. Limnology and Oceanography 50:587-597.

Babcock, R.C., B.L. Wills, and C.J. Simpson. 1994. Mass spawning of corals on a high latitude coral reef. Coral Reefs 13:161-169.
Bailey, K.M., and E.D. Houde. 1989. Predation on eggs and larvae of marine fishes and the recruitment problem. Advances in Marine Biology 25:1-83.

Barnett, A.M., and A.E. Jahn. 1987. Pattern and persistence of a nearshore planktonic ecosystem off Southern California. Continental Shelf Research 7:1-25.

Bassin, C.J., L. Washburn, M. Brzezinski, and E. McPhee-Shaw. 2005. Sub-mesoscale coastal eddies observed by high frequency radar: A new mechanism for delivering nutrients to kelp forests in the Southern California Bight. Geophysical Research Letters 32 (L12604):doi:10.1029/2005GL023017.

Baumann, H., H.H. Hinrichsen, R. Voss, D. Stepputtis, W. Grygiel, L.W. Clausen, and A. Temming. 2006. Linking growth to environmental histories in central Baltic young-of-the-year sprat, Sprattus sprattus: An approach based on otolith microstructure analysis and hydrodynamic modelling. Fisheries Oceanography 15(6):465-476.

Begon, M., J.L. Harper, and C.R. Townsend. 2006. Ecology. From individuals to ecosystems, 4 th ed. Blackwell Publishing, Malden, MA, 738 pp.

Bergenius, M.A.J., M.G. Meekan, D.R. Robertson, and M.I. McCormick. 2002. Larval growth predicts the recruitment success of a coral reef fish. Oecologia 131(4):521-525.

Berkeley, S.A., C. Chapman, and S.M. Sogard. 2004. Maternal age as a determinant of larval growth and survival in a marine fish. Sebastes melanops. Ecology 85(5):1,258-1,264.

Bingham, B.L., and C.M. Young. 1991. Larval behavior of the ascidian Ecteinascidia turbinata Herdman: An in situ experimental study of the effects of swimming of dispersal. Journal of Experimental Marine Biology and Ecology 145:189-204.

Blaxter, J.H.S. 1969. Development: Eggs and larvae. Pp. 177-252 in Fish Physiology, W.S. Hoar and D. J. Randall, eds, Academic Press, New York, NY.

Boehlert, G.W., and B.C. Mundy. 1988. Roles of behavioral and physical factors in larval and juvenile fish recruitment to estuarine nursery areas. Pp. 51-67 in Transport of Larval Fish and Shellfish Through Coastal Inlets, M.P. Weinstein, ed., Transactions of the American Fisheries Society Symposium 3.

Botsford, L.W., C.L. Moloney, A. Hastings, J.L. Largier, T.M. Powell, K. Higgins, and J.F. Quinn. 1994. The influence of spatially and temporally varying oceanographic conditions on meroplanktonic metapopulations. Deep-Sea Research II 41:107-145.

Bousfield, E.L. 1955. Ecological control of the occurrence of barnacles in the Miramichi estuary. National Museum of Canada Bulletin 137:1-69.

Brink, K.H. 1999. Observational coastal oceanography. Pp. 137-158 in The Future of Physical Oceanography: Report of the APROPOS Workshop. UCAR/JOSS.

Brown, C.A., S.A. Holt, G.A. Jackson, D.A. Brooks, and G.J. Holt. 2004. Simulating larval supply to estuarine nursery areas: How important are physical processes to the supply of larvae to the Aransas 
Pass Inlet? Fisheries Oceanography 13(3):181-196. Caley, M.J., M.H. Carr, M.A. Hixon, T.P. Hughes, G.P. Jones, and B.A. Menge. 1996. Recruitment and the local dynamics of open marine populations. Annual Review of Ecology and Systematics 27:477-500.

Carr, S.D., R.A. Tankersley, J.L. Hench, R.B. Forward Jr., and R.A. Luettich Jr. 2004. Movement patterns and trajectories of ovigerous blue crabs Callinectes sapidus during the spawning migration. Estuarine, Coastal and Shelf Science 60:567-579.

Chen, C., R.C. Beardsley, and G. Cowles. 2006. An unstructured-grid, finite-volume coastal ocean model (FVCOM) system. Oceanography 19(1):78-89.

Clobert, J., E. Danchin, A.A. Dhondt, and J.D. Nichols, eds. 2001. Dispersal. Oxford University Press, $452 \mathrm{pp}$.

Colby, D.R. 1988. Null hypotheses, models, and statistical designs in the study of larval transport. American Fisheries Society Symposium 3:149-162.

Cowen, R.K. 1991. Variation in the planktonic larval duration of the temperate wrasse Semicossyphus pulcher. Marine Ecology Progress Series 69:9-15.

Cowen, R.K. 2002. Larval dispersal and retention and consequences for population connectivity. Pp. 149170 in Coral Reef Fishes. Dynamics and Diversity in a Complex Ecosystem. P.F. Sale, ed., Academic Press, San Diego, CA.

Cowen, R.K., J.A. Hare, and M.P. Fahay. 1993. Beyond hydrography: Can physical processes explain larval fish assemblages within the Middle Atlantic Bight. Bulletin of Marine Science 53(2):567-587.

Cowen, R.K., K.M.M. Lwiza, S. Sponaugle, C.B. Paris, and D.B. Olson. 2000. Connectivity of marine populations: Open or closed? Science 287:857-859.

Cowen, R.K., C.B. Paris, and A. Srinivasan. 2006. Scaling of population connectivity in marine populations. Science 311:522-527.

Crisp, D.J. 1976. Settlement responses in marine organisms. Pp. 83-124 in Adaptation to Environment: Essays on the Physiology of Marine Animals, R.C. Newell, ed., Butterworths, London.

Cruz, T. 2000. Biologia e ecologia do percebe Pollicipes pollicipes (Gmelin, 1790) no litoral sudoeste português. Ph.D. Dissertation, Universidade de Évora, Évora.

Cushing, D.H. 1990. Plankton production and yearclass strength in fish populations: An update of the match/mismatch hypothesis. Advances in Marine Biology 26:249-293.

DiBacco, C., D. Sutton, and L. McConnico. 2001. Vertical migration behavior and horizontal distribution of brachyuran larvae in a low-inflow estuary: Implications for bay-ocean exchange. Marine Ecology Progress Series 217:191-206.

Doherty, P.J., V. Dufour, R. Galzin, M.A. Hixon, M.G. Meekan, and S. Planes. 2004. High mortality during settlement is a population bottleneck for a tropical surgeonfish. Ecology 85:2,422-2,428.

Edwards, K.P., J.A. Hare, F.E. Werner, and H. Seim. In press. Using two-dimensional dispersal kernels to identify the dominant influences on larval dispersal on continental shelves. Marine Ecology Progress Series.

Ellien, C., E. Thièbaut, F. Dumas, J.C. Salomon, and P. Nival. 2004. A modelling study of the respective role of hydrodynamic processes and larval mortality on larval dispersal and recruitment of benthic invertebrates: Example of Pectinaria koreni (Annelida: Polychaeta) in the Bay of Seine (English Channel). Journal of Plankton Research 26:117-132.

Fiksen, Ø., C. Jørgensen, T. Kristiansen, F. Vikebø, and G. Huse. In press. Linking behavioural ecology and oceanography: Larval behaviour determines growth, mortality and dispersal. Marine Ecology Progress Series.

Forward, R.B., J.H. Cohen, R.D. Irvine, J.L. Lax, R. Mitchell, A.M. Schick, M.M. Smith, J.M. Thompson, and J.I. Venezia. 2004. Settlement of blue crab Callinectes sapidus megalopae in a North Carolina estuary. Marine Ecology Progress Series 269:237-247.

Franks, P.J.S. 1992. Sink or swim: Accumulation of biomass on fronts. Marine Ecology Progress Series 82:1-12.

Garvine, R.W., C.E. Epifanio, C.C. Epifanio, and K.C. Wong. 1997. Transport and recruitment of blue crab larvae: A model with advection and mortality. Estuarine Coastal and Shelf Science 45(1):99-111.

Gaylord, B., and S.D. Gaines. 2000. Temperature or transport? Range limits in marine species mediated solely by flow. American Naturalist 55:769-789.

Gerlach, G., J. Atema, M.J. Kingsford, K.P. Black, and V. Miller-Sims. 2007. Smelling home can prevent dispersal of reef fish larvae. Proceedings of the National Academy of Sciences of United States of America 104:858-863.

Gerrodette, T. 1981. Dispersal of the solitary coral Balanophyllia elegans by demersal planular larvae. Ecology 62:611-619.

Giménez, L., and K. Anger. 2003. Larval performance in an estuarine crab, Chasmagnathus granulata, is a consequence of both larval and embryonic experience. Marine Ecology Progress Series 249:251-264.

Goffredi, S. K., W.J. Jones, C.A. Scholin, R. Marin, and R.C. Vrijenhoek. 2006. Molecular detection of marine invertebrate larvae. Marine Biotechnology 8:149-160.

Grimes, C.B., and M.J. Kingsford. 1996. How do riverine plumes of different sizes influence fish larvae: Do they enhance recruitment? Marine and Freshwater Research 47(2):191-208.

Hare, J.A., J.H. Churchill, R.K. Cowen, T.J. Berger, P.C. Cornillon, P. Dragos, S.M. Glenn, J.J. Govoni, and T.N. Lee. 2002. Routes and rates of larval fish transport from the southeast to the northeast United States continental shelf. Limnology and Oceanography 47:1,774-1,789.

Hare, J.A., and R.K. Cowen. 1997. Size, growth, development, and survival of the planktonic larvae of Pomatomus saltatrix (Pisces: Pomatomidae).
Ecology 78:2,415-2,431.

Hare, J.A., J.A. Quinlan, F.E. Werner, B.O. Blanton, J.J. Govoni, R.B. Forward, L.R. Settle, and D.E. Hoss. 1999. Larval transport during winter in the SABRE study area: Results of a coupled vertical larval behavior-three-dimensional circulation model. Fisheries Oceanography 8(supplement 1):57-76.

Hare, J.A., S.R. Thorrold, H. Walsh, C. Reiss, A. Valle-Levinson, and C. Jones. 2005. Routes and rates of larval fish transport from the southeast to the northeast United States continental shelf. Biophysical Mechanisms of Larval Fish Ingress into Chesapeake Bay 303:295-310.

Hentschel, B.T., and R.B. Emlet. 2000. Metamorphosis of barnacle nauplii: Effects of food variability and a comparison with amphibian models. Ecology 81:3,495-3,508.

Heyman, W.D., B. Kjerfve, R.T. Graham, K.L. Rhodes, and L. Garbutt. 2005. Spawning aggregations of Lutjanus cyanopterus (Cuvier) on the Belize Barrier Reef over a 6 year period. Journal of Fish Biology 67:83-101.

Hiatt, R.W. 1948. The biology of the lined shore crab, Pachygrapsus crassipes Randall. Pacific Science 2:135-213.

Hickey, B.M. 1979. The California Current Systemhypotheses and facts. Progress in Oceanography 8:191-279.

Hill, A.E. 1991. Advection-diffusion-mortality solutions for investigating pelagic larval dispersal. Marine Ecology Progress Series 70:117-128.

Houde, E.D. 1989. Comparative growth, mortality, and energetics of marine fish larvae: Temperature and implied latitudinal effects. Fishery Bulletin 87(3):471-495.

Hughes, T.P., A.H. Baird, E.A. Dinsdale, N.A. Moltschaniwskyj, M.S. Pratchett, J.E. Tanner, and B.L. Willis. 2000. Supply-side ecology works both ways: The link between benthic adults, fecundity, and larval recruits. Ecology 81:2,241-2,249.

Hunt, H.L., and R.E. Scheibling. 1997. Role of early post-settlement mortality in recruitment of benthic marine invertebrates. Marine Ecology Progress Series 155:269-301.

Jarrett, J.N. 2003. Seasonal variation in larval condition and postsettlement performance of the barnacle Semibalanus balanoides. Ecology 84(2):384-390.

Jeffs, A.G., and R.C. Holland. 2000. Swimming behaviour of the puerulus of the spiny lobster Jasus edwardsii (Hutton, 1875) (Decapoda, Palinuridae). Crustaceana 73:847-856.

Jenkins, G.P., and D. King. 2006. Variation in larval growth can predict the recruitment of a temperate, seagrass-associated fish. Oecologia 147(4):641-649.

Johnson, M.W. 1939. The correlation of water movements and dispersal of pelagic larval stages of certain littoral animals, especially the sand crab, Emerita. Journal of Marine Research 2:236-245.

Jones, G.P., S. Planes, and S.R. Thorrold. 2005. Coral reef fish larvae settle close to home. Current Biology 15:1,314-1,318. 
Kelly, P., S.D. Sulkin, and W.F van Heukelem. 1982. A dispersal model for larvae of the deep sea red crab Geryon quinquedens based on behavioral regulation of vertical migration in the hatching stage. Marine Biology 72:35-43.

Kingsford, M.J. 1990. Linear oceanographic features: A focus for research on recruitment processes. Australian Journal of Ecology 15:391-401.

Kingsford, M.J., J. Leis, A.L. Shanks, K. Lindeman, S. Morgan, and J. Pineda. 2002. Sensory environments, larval abilities and local self-recruitment. Bulletin of Marine Science 49:309-340.

Largier, J.G. 2003. Considerations in estimating larval dispersal distances from oceanographic data. Ecological Applications 13:S71-S89.

Lasker, R. 1975. Field criteria for survival of anchovy larvae: The relation between inshore chlorophyll maximum and successful feeding. U.S. Fish and Wildlife Service Fishery Bulletin 73:453-462.

Leaman, K.D., E. Johns, and T. Rossby. 1989. The average distribution of volume transport and potential vorticity with temperature at 3 sections across the Gulf Stream. Journal of Physical Oceanography 19:35-51.

Lee, O., B.S. Danilowicz, and M. Dickey-Collas. 2006. Temporal and spatial variability in growth and condition of dab (Limanda limanda) and sprat (Sprattus sprattus) larvae in the Irish Sea. Fisheries Oceanography 15(6):490-507.

Leis, J. 2006. Are larvae of demersal fishes plankton or nekton? Advances in Marine Biology 51:57-141.

Lentz, S.J. 1995. Sensitivity of the inner-shelf circulation to the form of the eddy viscosity profile. Journal of Physical Oceanography 25:19-28.

Lentz, S.J., R.T. Guza, S. Elgar, F. Feddersen, and T.H.C. Herbes. 1999. Momentum balances in the North Carolina inner shelf. Journal of Geophysical Research 104:18,205-18,226.

Levin, L.A. 2006. Recent progress in understanding larval dispersal: New directions and digressions. Integrative and Comparative Biology 282-297.

Levin, L.A., and T.S. Bridges. 1995. Pattern and diversity in reproduction and development. Pp. 1-48 in Ecology of Marine Invertebrate Larvae, $\mathrm{L}$. McEdward, ed., CRC Press, Boca Raton, FL.

Limouzy-Paris, C.B., H.C. Graber, D.L. Jones, A.W. Röpke, and W.J. Richards. 1997. Translocation of larval coral reef-fishes via sub-mesoscale spin-off eddies from the Florida Current. Bulletin of Marine Science 60:966-983.

Lough, R.G., L.J. Buckley, F.E. Werner, J.A. Quinlan, and K. Pehrson Edwards. 2005. A general biophysical model of larval cod (Gadus morhua) growth applied to populations on Georges Bank. Fisheries Oceanography 14:241-262.

Ma, H., and J.P. Grassle. 2005. Invertebrate larval availability during summer upwelling and downwelling on the inner continental shelf off New Jersey. Journal of Marine Research 62:837-865.

Macho, G., J. Molares, and E. Vásquez. 2005. Timing of larval release by three barnacles from the NW
Iberian Peninsula. Marine Ecology Progress Series 298:251-260.

Marshall, D.J., C.N. Cook, and R.B. Emlet. 2006. Offspring size effects mediate competitive interactions in a colonial marine invertebrate. Ecology 87(1):214-225.

Marshall, D.J., and M.J. Keough. 2006. Complex life cycles and offspring provisioning in marine invertebrates. Integrative and Comparative Biology 46(5):643-651.

Matsuura, Y., and R. Hewitt. 1995. Changes in the spatial patchiness of Pacific mackerel, Scomber japonicus, larvae with increasing age and size. Fishery Bulletin 93:172-178.

McCormick, M.I. 2006. Mothers matter: Crowding leads to stressed mothers and smaller offspring in marine fish. Ecology 87(5):1,104-1,109.

McCormick, M.I., and A.S. Hoey. 2004. Larval growth history determines juvenile growth and survival in a tropical marine fish. Oikos 106(2):225-242.

Meekan, M.G., J.H. Carleton, A.D. McKinnon, K. Flynn, and M. Furnas. 2003. What determines the growth of tropical reef fish larvae in the plankton: Food or temperature? Marine Ecology Progress Series 256:193-204.

Meekan, M.G., and L. Fortier. 1996. Selection for fast growth during the larval life of Atlantic cod Gadus morhua on the Scotian Shelf. Marine Ecology Progress Series 137(1-3):25-37.

Meekan, M.G., L. Vigliola, A. Hansen, P.J. Doherty, A. Halford, and J.H. Carleton. 2006. Bigger is better: Size-selective mortality throughout the life history of a fast-growing clupeid, Spratelloides gracilis. Marine Ecology Progress Series 317:237-244.

Metaxas, A. 2001. Behaviour in flow: Perspectives on the distribution and dispersion of meroplanktonic larvae in the water column. Canadian Journal of Fisheries and Aquatic Sciences 58:86-98.

Miller, T.J., L.B. Crowder, J.A. Rice, and E.A. Marschall. 1988. Larval size and recruitment mechanisms in fishes: Towards a conceptual framework. Canadian Journal of Fisheries and Aquatic Sciences 45:1,657-1,670.

Mitchum, G.T., and A.J. Clarke. 1986. The frictional nearshore response to forcing by synoptic scale winds. Journal of Physical Oceanography 16:934-946

Monismith, S.G., and D.A. Fong. 2004. A note on the potential transport of scalars and organisms by surface waves. Limnology and Oceanography 49:1,214-1,217.

Moran, A.L., and R.B. Emlet. 2001. Offspring size and performance in variable environments: Field studies on a marine snail. Ecology 82(6):1,597-1,612.

Morgan, S.G. 1995. The timing of larval release. Pp. 157-191 in Ecology of Marine Invertebrate Larvae, L. McEdward, ed., CRC Press, Boca Raton, FL. Mullin, M.M. 1993. Webs and Scales: Physical and Ecological Processes in Marine Fish Recruitment. Washington Sea Grant Program, University of Washington Press, Seattle, WA, 135 pp.
Nathan, R., and H. Muller-Landau. 2000. Spatial patterns of seed dispersal, their determinants and consequences for recruitment. Trends in Ecology and Evolution 15:278-285.

Natunewicz, C.C., and C.E. Epifanio. 2001. Spatial and temporal scales of patches of crab larvae in coastal waters. Marine Ecology Progress Series 212:217-222.

Nelson, J. 1912. Report of the biologist. Pp. 269-309 in Report of the Department of Biology, New Jersey Agricultural College Experimental Station for 1911.

O'Connor, M.I., J.F. Bruno, S.D. Gaines, B.S. Halpern, S.E. Lester, B.P. Kinlan, and J.M. Weiss. 2007. Temperature control of larval dispersal and the implications for marine ecology, evolution, and conservation. Proceedings of the National Academy of Sciences of the United States of America 104:1,266-1,271.

Okubo, A. 1988. Biological vortex rings fertilization and dispersal of fish eggs. Pp. 270-283 in Mathematical Ecology, T.G. Hallam, L.J. Gross, and S.A. Levin, eds, World Scientific, Singapore.

Okubo, A. 1994. The role of diffusion and related physical processes in dispersal and recruitment of marine populations. Pp. 5-32 in The Bio-Physics of Marine Larval Dispersal, P.W. Sammarco and M.L. Heron, eds, American Geophysical Union, Washington, D.C.

Olson, R.R., and R. McPherson. 1987. Potential vs. realized larval dispersal: Fish predation on larvae of the ascidian Lissoclinum patella (Gottschaldt). Journal of Experimental Marine Biology and Ecology 110:245-256.

Paris, C.B., R.K. Cowen, R. Claro, and K.C. Lindeman. 2005. Larval transport pathways from Cuban snapper (Lutjanidae) spawning aggregations based on biophysical modeling. Marine Ecology Progress Series 296:93-106.

Paris, C.B., and R.K. Cowen. 2004. Direct evidence of a biophysical retention mechanism for coral reef fish larvae. Limnology and Oceanography 49:1,964-1,979.

Pechenik, J.A. 1986. Field evidence for delayed metamorphosis of larval gastropods: Crepidula plana Say, C. fornicata (L.) and Bittium alternatum (Say). Journal of Experimental Marine Biology and Ecology 97:313-319.

Pechenik, J.A., J.N. Jarrett, and J. Rooney. 2002. Relationships between larval nutritional experience, larval growth rates, juvenile growth rates, and juvenile feeding rates in the prosobranch gastropod Crepidula fornicata. Journal of Experimental Marine Biology and Ecology 280(1-2):63-78.

Pechenik, J.A., D.E. Wendt, and J.N. Jarrett. 1998. Metamorphosis is not a new beginning. Bioscience 48:901-910.

Pepin, P., and J.A. Helbig. 1997. Distribution and drift of Atlantic cod (Gadus morhua) eggs and larvae on the northeast Newfoundland Shelf. Canadian Journal of Fisheries and Aquatic Sciences 54:670-685.

Phillips, N.E. 2004. Variable timing of larval food has 
consequences for early juvenile performance in a marine mussel. Ecology 85(8):2,341-2,346.

Pineda, J. 1994. Internal tidal bores in the nearshore: Warm-water fronts, seaward gravity currents and the onshore transport of neustonic larvae. Journal of Marine Research 52:427-458.

Pineda, J. 1999. Circulation and larval distribution in internal tidal bore warm fronts. Limnology and Oceanography 44:1,400-1,414.

Pineda, J. 2000. Linking larval settlement to larval transport: Assumptions, potentials, and pitfalls. Oceanography of the Eastern Pacific I:84-105.

Pineda, J., and M. López. 2002. Temperature, stratification and barnacle larval settlement in two Californian sites. Continental Shelf Research 22:1,183-1,198.

Pineda, J., V.R. Starczak, and T. Stueckle. 2006. Timing of successful settlement: Demonstration of a recruitment window in Semibalanus balanoides. Marine Ecology Progress Series 320:233-237.

Podolsky, R.D., and A.L. Moran. 2006. Integrating function across marine life cycles. Integrative and Comparative Biology 46(5):577-586.

Pritchard, D.W. 1953. Distribution of oyster larvae in relation to hydrographic conditions. Proceedings of the Gulf and Caribbean Fisheries Institute 5:123-132.

Queiroga, H., M.J. Almeida, T. Alpuim, A.A.V. Flores, S. Francisco, I. Gonzàlez-Gordillo, A.I. Miranda, I. Silva, and J. Paula. 2006. Tide and wind control of megalopal supply to estuarine crab populations on the Portuguese west coast. Marine Ecology Progress Series 307:21-36.

Quinlan, J.A., B.O. Blanton, T.J. Miller, and F.E. Werner. 1999. From spawning grounds to estuary: Using linked individual-based and hydrodynamic models to interpret patterns and processes in the oceanic phase of Atlantic menhaden Brevoortia tyrannus life history. Fisheries Oceanography 8(s2):224-246.

Radtke, R.L., R.A. Kinzie, and S.D. Folsom. 1988. Age at recruitment of Hawaiian freshwater gobies. Environmental Biology of Fishes 23:205-213.

Raimondi, P.T. 1991. Settlement behavior of Chthamalus anisopoma larvae largely determines the adult distribution. Oecologia (Berl.) 85:349-360.

Reyns, N.B., D.B. Eggleston, and R.A. Luettich. 2006. Secondary dispersal of early juvenile blue crabs within a wind-driven estuary. Limnology and Oceanography 51:1,982-1,995.

Roughgarden, J., S. Gaines, and H. Possingham. 1988. Recruitment dynamics in complex life cycles. Science 241:1,460-1,466.

Rumrill, S.S. 1990. Natural mortality of marine invertebrate larvae. Ophelia 32:163-198.

Sammarco, P.W., and J.C. Andrews. 1989. The Helix experiment: Differential localized dispersal and recruitment patterns in Great Barrier reef corals. Limnology and Oceanography 34:896-912.

Scheltema, R.S. 1986. On dispersal and planktonic larvae of benthic invertebrates: An eclectic overview and summary of problems. Bulletin of Marine Science 39:290-322.

Scheltema, R.S., and I.P. Williams. 1982. Significance of temperature to larval survival and length of development in Balanus eburneus (Crustacea: Cirripedia). Marine Ecology Progress Series 9:43-49.

Scotti, A., and J. Pineda. 2007. Plankton accumulation and transport in propagating nonlinear internal fronts. Journal of Marine Research 65:117-145.

Searcy, S.P., and S. Sponaugle. 2001. Selective mortality during the larval-juvenile transition in two coral reef fishes. Ecology 82(9):2,452-2,470.

Shanks, A.L., B.A. Grantham, and M.E. Carr. 2003. Propagule dispersal distance and the size and spacing of marine reserves. Ecological Applications 13: S159-S169.

Siegel, D.A., B.P. Kinlan, B. Gaylord, and S.D. Gaines. 2003. Lagrangian descriptions of marine larval dispersion. Marine Ecology Progress Series 260:83-96.

Simpson, J.J. 1984. El Niño-induced onshore transport in the California Current during 19821983. Geophysical Research Letters 11:233-266.

Sinclair, M. 1988. Marine Populations: An Essay on Population Regulation and Speciation. Washington Sea Grant Program, Seattle, WA, 252 pp.

Sponaugle, S., T. Lee, V. Kourafalou, and D. Pinkard. 2005. Florida Current frontal eddies and the settlement of coral reef fishes. Limnology and Oceanography 50:1,033-1,048.

Sponaugle, S., R.K. Cowen, A.L. Shanks, S.G. Morgan, J. Leis, J. Pineda, G. Boehlert, M.J. Kingsford, K. Lindeman, C. Grimes, and J.L. Munro. 2002. Predicting self-recruitment in marine populations: Biophysical correlates and mechanisms. Bulletin of Marine Science 49:341-375.

Sponaugle, S., and K. Grorud-Colvert. 2006. Environmental variability, early life-history traits, and survival of new coral reef fish recruits. Integrative and Comparative Biology 46:623-633.

Sponaugle, S., K. Grorud-Colvert, and D. Pinkard. 2006. Temperature-mediated variation in early life history traits and recruitment success of the coral reef fish Thalassoma bifasciatum in the Florida Keys. Marine Ecology Progress Series 308:1-15.

Sponaugle, S., and D.R. Pinkard. 2004. Impact of variable pelagic environments on natural larval growth and recruitment of the reef fish Thalassoma bifasciatum. Journal of Fish Biology 64(1):34-54.

Stobutzki, I.C. 1997. Energetic cost of sustained swimming in the late pelagic stages of reef fishes. Marine Ecology Progress Series 152(1-3):249-259.

Stommel, H. 1963. Varieties of oceanographic experience. Science 139:572-576.

Suthers, I.M., J.J. Cleary, S.C. Battaglene, and R. Evans. 1996. Relative RNA content as a measure of condition in larval and juvenile fish. Marine and Freshwater Research 47 (2):301-307.

Tapia, F., and J. Pineda. 2007. Stage-specific distribution of barnacle larvae in nearshore waters: Potential for limited dispersal and high mortality rates. Marine Ecology Progress Series 342:177-190.

Tapia, F., J. Pineda, F. Ocampo-Torres, H. Fuchs, E. Parnell, P. Montero, and S. Ramos. 2004. High-frequency observations of wind-forced onshore transport at a coastal site in Baja California. Continental Shelf Research 24:1,573-1,585.

Thièbaut, E., J.C. Dauvin, and Y. Lagadeuc. 1992. Transport of Owenia fusiformis larvae (Annelida: Polychaeta) in the Bay of Seine. I. Vertical distribution in relation to water column stratification and ontogenic vertical migration. Marine Ecology Progress Series 80:29-39.

Titelman, J., and O. Fiksen. 2004. Ontogenetic vertical distribution patterns in small copepods: Field observations and model predictions. Marine Ecology Progress Series 284:49-63.

Villanueva, R., C. Nozais, and S. v. Boletzky. 1996. Swimming behaviour and food searching in planktonic Octopus vulgaris Cuvier from hatching to settlement. Journal of Experimental Marine Biology and Ecology 208:169-184.

Walsh, H.J., K.E. Marancik, and J.A. Hare. 2006. Juvenile fish assemblages collected on unconsolidated sediments of the southeast United States continental shelf. Fishery Bulletin 104:256-277.

Warner, R.R. 1988. Traditionality of matingsite preferences in a coral-reef fish. Nature 335(6,192):719-721.

Webster, M.S., P.P. Marra, S.M. Haig, S. Bensch, and R.T. Holmes. 2002. Links between worlds: Unraveling migratory connectivity. Trends in Ecology and Evolution 17:76-83.

Wilbur, H.M. 1980. Complex life cycles. Annual Review of Ecology and Systematics 11:67-93.

Willis, B.L., and J.K. Oliver. 1990. Direct tracking of coral larvae: Implications for dispersal studies of planktonic larvae in topographically complex environments. Ophelia 32:145-162.

Winant, C.D. 1983. Longshore coherence of currents on the Southern California shelf during the summer. Journal of Physical Oceanography 13:54-64.

Winant, C.D., and A. Bratkovich. 1981. Temperature and currents in the southern California shelf: A description of the variability. Journal of Physical Oceanography 11:71-86.

Woods, L., and W.J. Hargis. 1971. Transport of bivalve larvae in a tidal estuary. Pp. 29-44 in Fourth European Marine Biology Symposium, D.J. Crisp, ed., Cambridge University Press.

Zimmerman, R.C., and D.L. Robertson. 1985. Effects of El Niño on local hydrography and growth of the giant kelp, Macrocystis pyrifera, at Santa Catalina Island, California. Limnology and Oceanography 30:1,298-1,302. 